\title{
CHANGES IN THE LIPID COMPOSITION OF ANTERIOR HYPOPHYSIS, BLOOD PLASMA AND LIVER
}

\author{
II. HISTOLOGICAL GHANGES IN THE ANTERIOR HYPOPHYSIS; \\ IN THE FOETUS AND ITS DAM IN THE BOVINE
}

\section{BALWANT AHLUWALIA,* ABUBAKAR SHAIKH AND SUMIO SHIMA}

\author{
Worcester Foundation for Experimental Biology, \\ Shrewsbury, Massachusetts
}

(Received 26th March 1968, revised 6th August 1968)

Summary. Total lipid, total phospholipid and total fatty acid patterns of the anterior hypophysis, blood plasma and liver of foetuses and their dams at 4- and 8-month gestation intervals were determined.

Differences in total lipid and total phospholipid between foetuses of different ages and their dams were not significant, and the differences in total fatty acid pattern among the foetuses and among the dams were minor at either time.

Differences were significant in the total fatty acid patterns between the foetuses and their dams. The differences were mostly in the concentra-

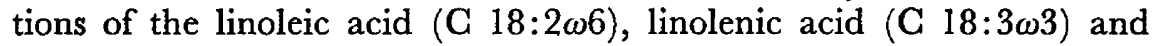
oleic acid (C 18:1 $\omega 9$ ) families of fatty acids. The concentration of linoleic acid in various tissues of the dam was significantly higher than in the foetus, but arachidonic acid (C 20:4 $\omega 6$, a major metabolite of linoleic acid) was significantly lower in the plasma and liver of the dam than in the foetus; in the anterior hypophysis the differences were not significant.

Linolenic acid (C 18:3 $\omega 3$ ) was either absent or present in trace amounts $(<0.1 \%)$ in the foetal tissues; in the dam it was present in significant amounts $(1.5$ to $5 \%)$.

In the dams, oleic acid concentration was significantly lower than in the foetus in the plasma and anterior hypophysis and somewhat higher in the liver.

Microscopic examination of the anterior hypophysis of the foetus showed mainly undifferentiated chromophobes with a few sparsely granulated acidophil cells; in the dam, the gland was composed mainly of clumps of acidophils and a few chromophobes.

* Present address: Building 10, Room SN-102, National Institutes of Health, Bethesda, Maryland 20014. 


\section{INTRODUCTION}

Little is known of the changes in the lipid composition of organs during foetal development. Ahluwalia \& Holman (1966) described the changes in the lipid composition of testes in neonatal and postnatal animals in the bovine; they found an increase in the concentrations of linoleic acid, linolenic acid and their metabolites and a decrease in oleic acid concentrations in the growing foetus and in postnatal animals up to the age of puberty. Dobiasová, Hahn \& Koldovsky (1964) studied the fatty acid composition of phospholipids and triglycerides in various tissues of the developing rat. The data reported by these authors indicate that the fatty acid composition differed within tissues and with age during development. Kirschman \& Coniglio (1961) described the changes in the concentrations of polyenoic acids in the weanling, 3-month- and 6-monthold rat; a selective increase in the polyenes in various tissues was found in the growing animal. Other reports describe the changes in the concentrations of major lipid fractions in the blood plasma of calves (from birth to 6 months of age) (Shannon \& Lascelles, 1966), and phospholipid patterns in the subcellular fractions of adult and immature rat organs (Biezenski, Spaet \& Gordon, 1963). These studies indicate a broad pattern of differences in the concentration of total lipid and lipid components with the age of the animal.

The object of the present study was to determine the lipid changes in foetal and maternal organs during gestation before making a more detailed study of lipid transport across the placenta.

\section{MATERIALS AND METHODS}

Foetal and maternal specimens of liver, blood plasma and pituitary were taken from thirty-two pregnant cows of mixed breeds (Jersey $\times$ Holstein) at 4 and 8 months of gestation (sixteen in each group).

The length of gestation was determined on the basis of crown-rump measurements of the foetuses (Stoff, 1944). Because of the small size of the pituitaries in the foetuses, four organs were pooled in each group (four samples in each group); in the dams, the organs were not pooled and four samples were chosen randomly in each group (sixteen animals in each group). Liver and blood samples were not pooled in either dams or in the foetuses. A portion of liver $(20 \mathrm{~g})$ and $160 \mathrm{ml}$ of blood drawn from the umbilical vein of the foetuses and jugular vein of the dams were obtained from six animals chosen randomly in each group. The blood samples were heparinized.

The samples were kept frozen in normal saline at $-20^{\circ} \mathrm{C}$ until analysis.

\section{Lipid extraction and fatty acid determination by gas-liquid chromatography}

The tissues (liver and pituitaries) were thawed at the time of analysis and homogenized in an Omni mixer (Sarvall). The blood was centrifuged at $8000 \mathrm{~g}$ for $20 \mathrm{~min}$ at $4^{\circ} \mathrm{C}$ to separate the plasma. (Plasma constitutes about $44 \%$ of blood in the foetus, and $62 \%$ in the dams.) The lipids were extracted with 20 vols of chloroform and methanol $2: 1 \mathrm{v} / \mathrm{v}$ according to the method of Folch, Lee \& Sloan Stanley (1957). An aliquot of lipid from each tissue extract was 
esterified with $5 \% \mathrm{HCl}$ in methanol (anhydrous), and the fatty acid esters were extracted and analysed by gas-liquid chromatography. A detailed method for fatty acid estimation has been described previously (Ahluwalia \& Holman, 1966).

\section{Determination of total lipid and lipid classes}

An aliquot of lipid from each tissue was used for determination of total lipid gravimetrically. The results were expressed as percentage lipid per $100 \mathrm{~g}$ wet tissue.

Total phospholipid was determined by the phosphorous method of Fiske \& Subbarow (1925).

\section{Histological studies}

One organ from each group was chosen randomly and the anterior pituitary was separated from the posterior pituitary. A section was cut parallel to the horizontal plane and fixed in chromalum fixative for $24 \mathrm{hr}$ (Elftman, 1957). The sections $(6 \mu)$ were stained by luxol fast blue-PAS-haematoxylin (McManus \& Mowry, 1965).

\section{RESULTS}

The fatty acid composition of anterior hypophysis, liver and plasma in foetuses and dams is summarized in Table 1. No major differences were found in total fatty acid pattern in the tissues of dams at the two gestation periods; however, the differences between the foetuses and their dams were significant.

\section{Lipid composition of anterior hypophysis (Table 1)}

In the dams, the amount of linoleic acid $(\mathrm{C} 18: 2 \omega 6)$ was about four times higher than in the foetus while that of oleic acid $(\mathrm{C} 18: 1 \omega 9)$ was about half the foetal level. The concentration of major metabolites of linoleic acid

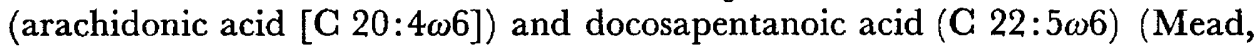
$1957,1960)$ were similar in the foetuses and their dams. Linolenic acid (C 18:3 $\omega 3$ ) was present in trace amounts in the foetuses but in significant amounts in the dams.

\section{Lipid composition of liver (Table 1)}

The fatty acid distribution in the livers of foetuses and dams (Table 1) presents a different picture from that of the anterior hypophysis. For example,

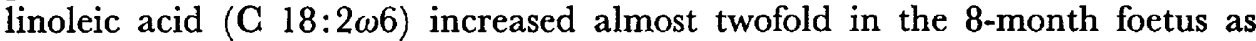
compared to the 4-month foetus and the differences between the 8-month foetus and the dams were approximately twofold. The concentration of arachidonic acid in the dam was about half that in the 8-month foetus.

\section{Lipid composition of plasma (Table 1)}

The differences in the concentration of individual fatty acids between the foetuses at the two gestation levels were slight; however, significant differences were found between the foetuses and their dams. For example, the level of 


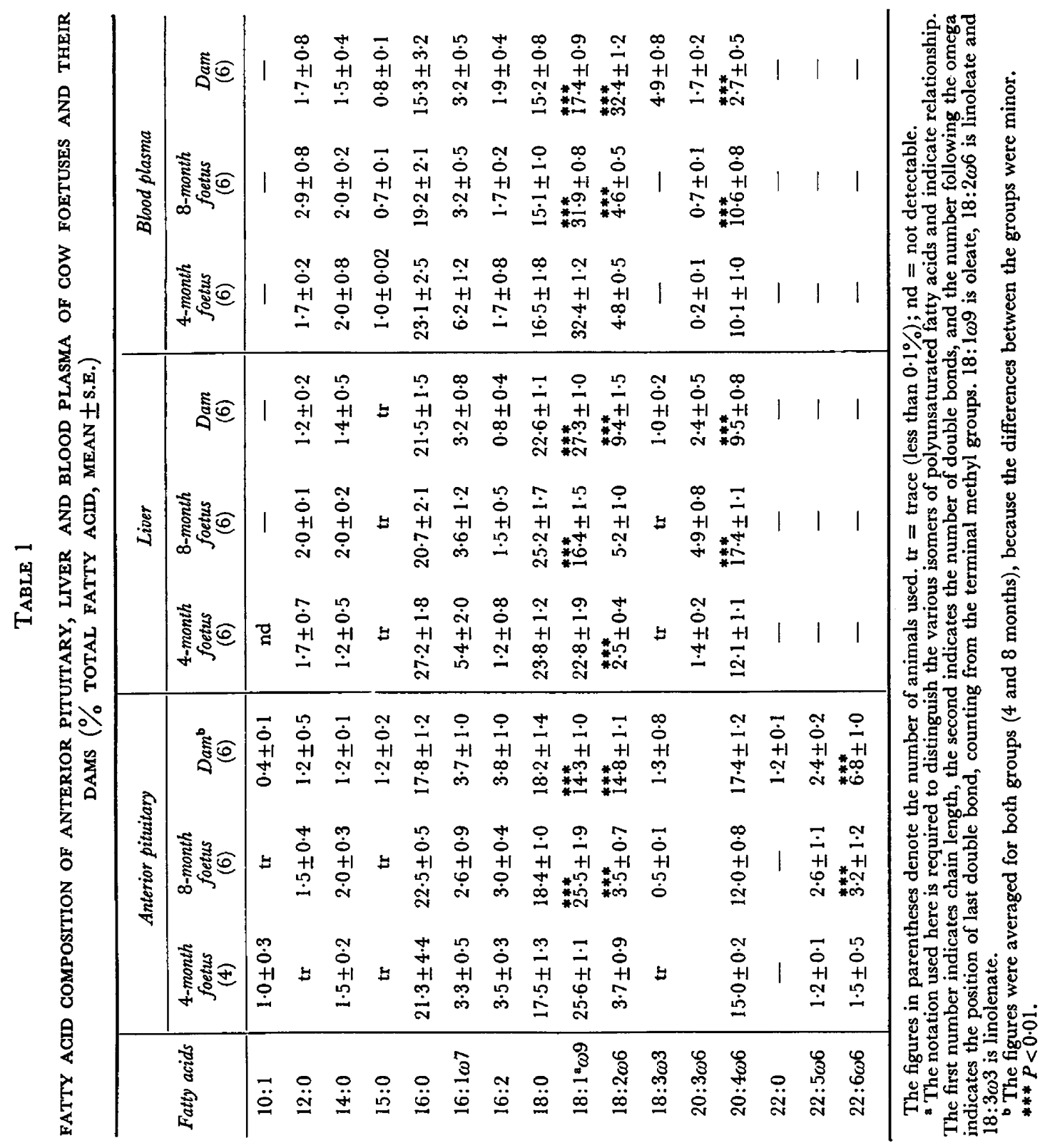




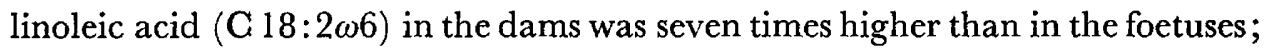
that of arachidonic acid was approximately one-fourth of the foetal level. Oleic acid (C 18:1 $\omega 9$ ) followed the reverse pattern of linoleic acid. Linolenic acid

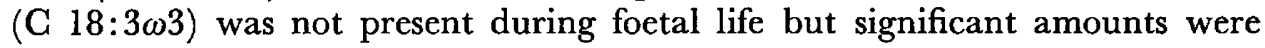
present in the dam $(5 \%)$.

\section{Total lipid and lipid components}

The total lipids (per $100 \mathrm{~g}$ tissue) and the percentage of phospholipids in total lipid are presented in Text-fig. 1. The differences between the foetuses

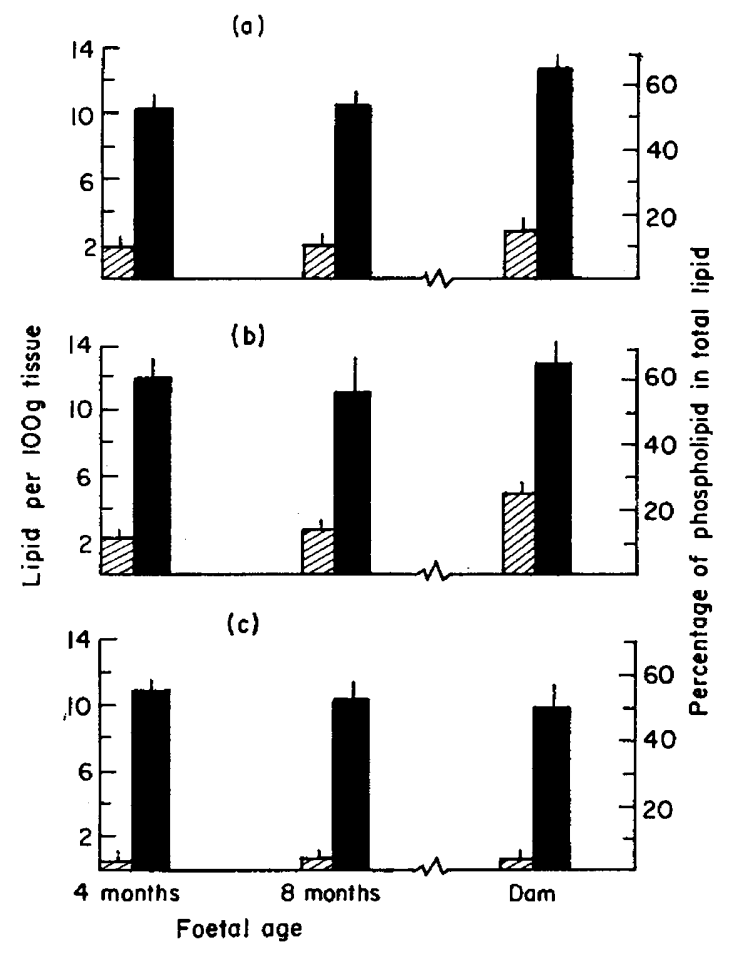

TeXT-Fig. 1. Comparison of total lipid (hatched columns) and total phospholipid (in total lipid) (solid columns) between foetal and maternal tissues. (a) Anterior hypophysis; (b) liver; (c) plasma. The differences within dams at either gestation level were not significant; therefore the figures at both gestation levels were averaged.

and between the dams in either gestation interval were minor; therefore, the figures were averaged in each group. There were minor differences in total lipid and phospholipid content in the foetuses and their dams. For example, in the pituitary (a) there was a slightly higher phospholipid content in the dam; in the liver (b) the figure obtained for total lipid was higher in the dam, but the differences were not significant (at the $5 \%$ level, the limit set in the experiment).

The histological picture of the anterior hypophysis of the 4-month foetus is similar to that at 8 months. The majority of cells are undifferentiated chromo- 
phobes with a few sparsely granulated acidophils and a few basophils (Pl. 1, Fig. 1a, b). No attempt was made to classify the various cells according to their shape. The description is based only on the staining properties of the cells.

\section{DISCUSSION}

From the data it is evident that, as in adults, there is a characteristic pattern of fatty acid distribution in various foetal organs. This pattern seems to develop very early. The differences in the concentration of individual fatty acids in the corresponding organ of foetus and dam (Table 1) may suggest either synthesis of lipids in the foetus or selective permeability of fatty acids by the placenta. Using radio-active isotopes in pregnant rabbits, Popjak \& Beeckmans (1950) demonstrated that foetal liver and embryonal adipose tissue can synthesize both saturated and unsaturated fatty acids and, in addition, foetal placenta can synthesize lipids; it also absorbs these from the maternal circulation.

In the present study, the most significant changes were found in the concentration of dienoic acid (C 18:2 $\omega 6)$. The low concentration of $(\mathbf{C} 18: 2 \omega 6)$

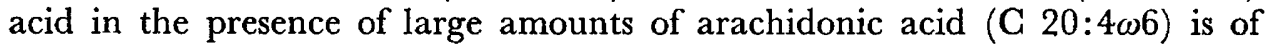
interest. A high concentration of arachidonic acid and a low concentration of linoleic acid in human foetal blood has been reported by Sprecher \& Robertson (1967). Kirschman \& Coniglio (1961) reported an increase in the amount of tetraenes $(20: 4 \omega 6)$ in the presence of trace amounts of dienes $(18: 2 \omega 6)$ in the brain tissue of developing male and female rats. These authors postulated that the increased concentration of $\mathrm{C} 20: 4 \omega 6$ may be due to a rapid turnover of C 18:2 $\omega 6$ or a blood-brain barrier to linoleic acid, but not to arachidonic acid. In view of the findings in guinea-pigs and rabbits (Satomura \& Söderhjelm, 1962; Söderhjelm, 1953), where the passage of unsaturated fatty acids including oleic acid and linoleic acids has been demonstrated, it would seem more likely that the presence of large amounts of $\mathrm{C} 20: 4 \omega 6$ and small amounts of $\mathrm{C} 18: 2 \omega 6$ in the foetus is due to increased conversion of linoleic acid rather than to a placental barrier. Body \& Shorland (1964) suggested the possibility of $\mathrm{C}_{20}$ fatty acids in the sheep being synthesized mainly in the foetus rather than transported across the placenta.

The fatty acid pattern in foetal liver, plasma and pituitary bears no similarity to that reported in foetal testes (Ahluwalia \& Holman, 1966) where the concentrations of linoleic acid and its metabolite increase somewhat in the growing foetus and continue to increase after birth up to puberty. Whether this is due to the characteristic pattern of individual organs or has some association with the functions of the gland cannot be determined here. However, it is interesting to note that the histological structure of the foetal testes (unpublished data) shows little or no evidence of differentiation into tubule and gonadal cells and the histological structure of the pituitary and liver (unpublished data) shows few resemblances to that of mature animals. The increased amount of arachidonic acid in the pituitary and liver in the foetus may have some association with the developmental aspects of these tissues. The presence of a few differentiated acidophils and basophils in the foetal pituitary may indicate that the gland is functional to some extent. However, to our knowledge, no study has 


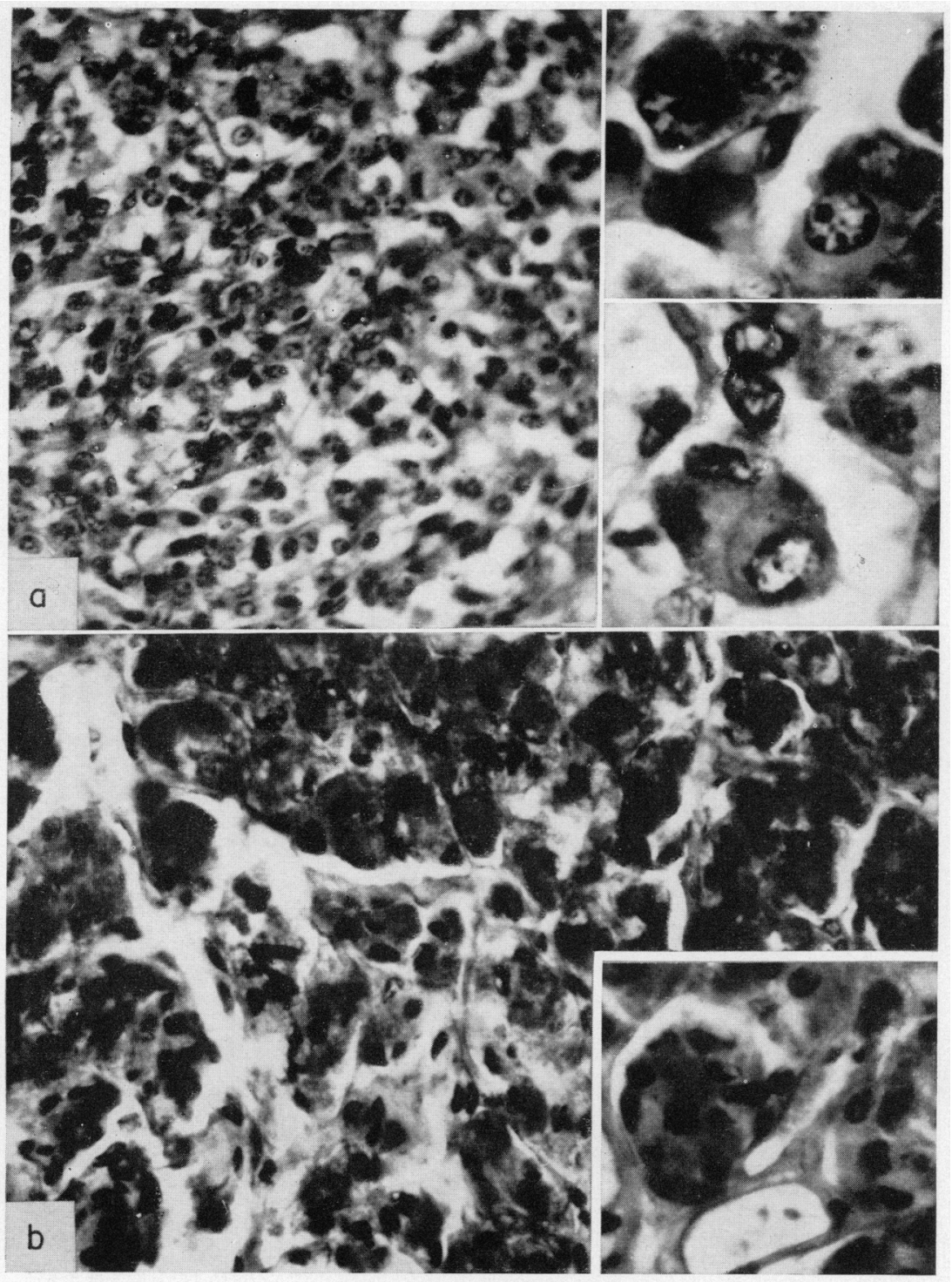

Fig. 1. (a) Foctal cow pituitary (8 months) stained with luxol fast bluc, P'AS, haematoxylin. Sparsely granulated acidophil cells are mingled with chromophobes and some pale basophils. $\times 750$.

Inset, top: high magnification of acidophils, red filter, $\times 67,50$.

Inset, bottom: high magnification of basophils, green filter, $\times 6750$.

(b) Adult cow pituitary stained with luxol fast blue, PAS, hacmatoxylin. The gland is composed mainly of clumps of acidophil cells surrounded by sinusoids and connective tissue strands. Few chromophobes can be identified and basophil cells are extremely rare. × 750 .

Inset: detail of acinar-looking accumulation of acidophil cells, red filter, $\times 3000$. 
been reported indicating the age at which the foetal hypophysis in the bovine becomes functional. In the human it has been reported that in the 10-week foetus, the gonadotrophic hormones are detectable when extracted and used experimentally (Arey, 1959). Studies are under way in the laboratory to determine the approximate age at which the bovine foetal pituitary has some function.

In summary, our studies demonstrate that fatty acids, which belong to the linoleic acid series and possess essential fatty acid properties, show the most changes in concentration in the developing animal, beginning in foetal life. It has been postulated that in the rat these fatty acids may have some biochemical significance (Aaes-Jørgensen, 1961; Davis, Bridges \& Coniglio, 1966).

\section{AGKNOWLEDGMENTS}

The author wishes to acknowledge a Special Fellowship Grant 1F3HD23,963-01, from the National Institutes of Health. This work was supported in part from a grant from G. D. Searle \& Co. and Grants AM-04524 and HE-08214 from National Institutes of Health, U.S. Public Health Service granted to Dr Ralph T. Holman, Hormel Institute, Austin, Minnesota.

\section{REFERENCES}

Aars-Jørgensen, E. (1961) Essential fatty acids. Physiol. Rev. 41, 40.

Ahluwalia, B. \& Holman, T. R. (1966) Fatty acid distribution in the bovine pre- and postpartum testis. Lipids, 1, 197.

AREY, L. B. (1959) The mouth and pharynx. In: Developmental Anatomy, 6th edn, p. 227. Saunders, Philadelphia.

Brezenski, J. J., Spaet, T. T. \& Gordon, A. L. (1963) Phospholipid patterns in subcellular fractions of adult- and immature-rat organs. Biochim. biophys. Acta, 70, 75.

Body, D. R. \& Shorland, F. B. (1964) Maternal and foetal lipids of sheep. Nature, Lond. 202, 769.

Davis, J. T., Bridges, R. B. \& Coniglio, J. G. (1966) Changes in lipid composition of the maturing rat testis. Biochem. F. 98, 342.

Dobiasová, M., Hahn, P. H. \& Koldovsky, O. (1964) Fatty acid composition in developing rats. Fatty acid composition of triglyceride and phospholipids in some organs of the rat during postnatal development. Biochim. biophys. Acta, 84, 538.

Elftman, H. (1957) A chrome-alum fixative for the pituitary. Stain Technol. 32, 25.

Fiske, C. H. \& Subbarow, Y. (1925) The colorimetric determination of phosphorus. 7. biol. Chem. 66, 375.

Folch, J., Lee, M. \& Sloan Stanlex, G. H. (1957) A simple method for the isolation and purification of total lipids from animal tissues. F. biol. Chem. 226, 497.

Kirschman, J. G. \& Coniglio, J. G. (1961) Polyunsaturated fatty acids in tissues of growing male and female rats. Archs Biochem. Biophys. 93, 297.

McManus, J. F. A. \& Mowry, R. W. (1965) Staining. In: Staining Methods, 3rd edn, p. 331. Harper and Row, New York.

MEAD, J. (1957) The metabolism of the essential fatty acids. VI. Distribution of unsaturated fatty acids in rats on fat free and supplemented diets. 7. biol. Chem. 227, 1025.

MEAD, J. F. (1960) The metabolism of the polyunsaturated fatty acids. Am. F. clin. Nutr. 8, 55.

Popjak, G. \& Beeckman, M. L. (1950) Synthesis of cholesterol and fatty acids in foetuses and in mammary glands of pregnant rabbits. Biochem. J. 46, 547.

Satomura, K. \& Söderhjelm, L. (1962) Deposition of fatty acids in the newborn in relation to the diet of pregnant guinea pigs. Tex. Rep. Biol. Med. 20,671.

Shannon, A. D. \& Lascelles, A. K. (1966) Changes in the concentration of lipids and some other constituents in the blood plasma of calves from birth to 6 months of age. Aust. J. biol. Sci. 19, 831. 
SöDERHJELM, L. (1953) Fat absorption studies. VI. The passage of polyunsaturated fatty acids through the placenta. VII. Polyunsaturated fatty acids of human milk and their variation with dietary fat. Acta Soc. Med. upsal. 58, 239.

Sprecher, H. \& Robertson, A. (1967) Analysis of lecithin and cephalin fatty acids from human maternal and fetal blood, perfused placenta, chorion laeve and amnion. F. Lab.clin. Med. 70, 489.

Storp, H. O. (1944) Tierartzliche GeburssKunde und Gynakologie. Enke, Stuttgart. 